\title{
Racialización de actores latinoamericanos $y$ africanos en la industria cultural de Madrid y el ilusorio blanqueamiento de lo español*
}

\author{
Racialisation of Latin American and African Actors \\ in Madrid's Cultural Industry \\ and the Illusory Whitening of Spanishness
}

\author{
Ángeles Montalvo Chaves ${ }^{1}$ \\ Investigadora independiente
}

\section{RESUMEN}

Este artículo corresponde a la investigación doctoral con organizaciones teatrales de latinoamericanos y africanos en Madrid ${ }^{2}$. Los resultados de este estudio destacan dos cuestiones fundamentales: 1) sujetos diferenciados bajo la postcolonialidad se representan en los medios de comunicación, en películas y series televisivas mayoritariamente desde formas racializadas y sexualizadas. 2) Estos mismos sujetos no cesan de responder a estas representaciones dominantes y de buscar espacios alternativos para expresar sus capacidades creativas más allá de estos prototipos racialmente diferenciados e inferiorizados. Como respuesta, actores de procedencia latinoamericana crean alianzas con actores africanos en la compañía teatral Entrecalles, donde generan resistencia. La unión dará lugar a la articulación de una identidad cultural y política bajo nomenclaturas que son cambiantes y re-articulables bajo signos contingentes como latinoamericano e inmigrante. Como argumento, la racialización de estas personas y su representación mediática alude además a un enraizado ilusorio blanqueamiento por el que se ha construido España como nación.

Palabras clave: Racialización postcolonial; Latinoamericanos; Africanos; Teatro; Industria cultural; Blanqueamiento español.

\section{SUMMARY}

This article relates to doctoral research undertaken with Latin American and African theatre organisations in Madrid. Findings highlight two fundamental questions: 1) subjects who are dif-

\footnotetext{
* Gracias a cada uno de los miembros de Entrecalles, así como al resto de actores que han participado en esta investigación. Muchas gracias por tener siempre esa disponibilidad para colaborar conmigo.

${ }^{1}$ Correo electrónico: angeles.montalvo@students.mq.edu.au. ORCID iD: <https://orcid.org/0000$0002-5702-827 \mathrm{X}>$.

${ }^{2}$ La tesis doctoral fue realizada bajo un acuerdo de cotutela entre la Macquarie University (Sídney, Australia) y la Universidad Autónoma de Madrid (España), con ayuda de la beca International Macquarie University Research Excellence Scholarship, concedida por la Macquarie University.
} 
ferentiated under postcoloniality are predominantly represented in mass media, films and TV series in racialised and sexualised ways; 2) the subjects in question continually respond to these dominant representations, looking for alternative spaces in which to express their creative abilities that go beyond such racialised and inferiorised prototypes. Rising to the challenge, actors from Latin American backgrounds have created alliances with African actors in the theatre company Entrecalles, where they generate resistance. Their union seeks to articulate a cultural and political identity under nomenclatures that are susceptible to change and re-articulation and under contingent signs like Latin American and immigrant. I argue that the racialisation of these people and their media representation also responds to a deep-rooted illusory whitening on which the nation of Spain has been built.

Keywords: Postcolonial Radicalisation; Latin Americans; Africans; Theatre; Cultural Industry; Spanish Whitening.

\section{INTRODUCCIÓN}

Mientras estoy escribiendo las primeras líneas de este artículo, cuatro años después del trabajo de campo de investigación doctoral, aparece una noticia en el periódico español eldiario.es (Gutiérrez 2017) que viene a denunciar lo que veremos en este trabajo. Personas asociadas al mundo de la interpretación y mediático exponen sus vivencias y discrepancias con las representaciones dominantes que de ellas se da en los mass media e industrias culturales españolas. Entre estas personas está Yu Fu, una mujer china que creó un canal en youtube desde donde intenta combatir estereotipos sobre chinos. Justo Salas, actor cubano y diecisiete años trabajando en España, cuya experiencia le permite afirmar que los papeles a los que puede optar se ciñen a los asociados con delincuencia o camarero. Pilar Pardo, una mujer española afrodescendiente y representante de actores, quien denuncia la "falta de atrevimiento" de las agencias por escoger actores negros para papeles de "no negros". Pardo añade un componente sexualizado y señala el caso de actrices negras para quienes los papeles se reducen a trabajadoras de limpieza, mujeres maltratadas o prostitutas. El título de la noticia es el de "A los actores negros nos obligan a poner acentos de África... ¡si soy de Móstoles!n, que sirve para introducir la mesa redonda organizada por SOS Racismo Madrid en la que estas personas, junto a Mohammed Alzabaz — mediador cultural madrileño que trabaja para combatir estereotipos sobre población árabe y musulmana a través del cómic - participan para tratar conjuntamente estas problemáticas.

Como veremos, estas voces críticas no son las primeras que surgen en España, pero la noticia viene a colación y sirve para introducir lo que observaremos en este artículo. Las personas que participaron en esta investigación - actrices y actores de ascendencia latinoamericana y africana- claman un similar tratamiento cuando han intentado acceder a papeles de películas y espacios mediáticos españoles. A través de la investigación etnográfica realizada durante trece meses, entre septiembre de 2012 y octubre de 2013, con observación participante y entrevistas a actores de la compañía latinoamericana de teatro en Madrid - Entrecalles- así como el análisis de películas, series de televisión y mass media ${ }^{3}$, veremos cuáles son los roles más repetitivos

\footnotetext{
${ }^{3}$ El trabajo de campo incluyó entrevistas formales a cada una de las personas que formaban Entrecalles, así como otros actores de procedencias latinoamericanas y africanas allegados a estos.
} 
por procedencia geográfica en la industria cultural y cómo determinan las características físicas y lingüísticas el acceso a esos papeles. La etnografía mostrará que en espacios alejados de dicha industria actores latinoamericanos se han aliado con actores africanos en un proyecto teatral conjunto desde donde generar resistencia. Para este análisis, será necesario cuestionarnos a qué o quiénes nos referimos cuando utilizamos los términos inmigrante o descendiente, y analizar cómo sigue actuando la idea de raza — articulado con otros marcadores como el sexual o lingüístico- en estas representaciones. Argumento que la idea de raza está inscrita en una antigua pero continuada dominación masculina, heterosexual y nacionalizada, enraizada en un ilusorio blanqueamiento sobre el que se ha construido lo español frente a minorías étnicas.

\title{
IDENTIDAD LATINOAMERICANA FRENTE A LA RACIALIZACIÓN DIFERENCIADA
}

\begin{abstract}
Antes, mi interés era el de ser actor. Pero era..., es complicado. Es aquí en España donde desarrollo más mi faceta de director, ya que como actor, estoy más limitado aquí. Siempre me llaman para hacer papeles de traficante o indigena tapa-rabos. Pero de hecho no me van a llamar por mis cualidades interpretativas. Así que eso me ha llevado a desarrollar más mi faceta de director (Carlos Alcalde, director de Entrecalles, entrevista personal, 11 mar. 2013).
\end{abstract}

Carlos no recuerda con exactitud la fecha en la que fundó Entrecalles, pero señala sobre 1995 en México, donde estuvo trabajando como actor y asistente de dirección. A México llegó desde su país, Perú, donde se había formado como actor. En México conoció a un director de teatro español que le ofreció trabajo en España, lo que le llevó a trasladarse a Madrid en el año 2000. Desde entonces, ha continuado trabajando en Entrecalles como director, guionista y actor, al mismo tiempo que de actor en películas y series de televisión. Como él menciona, sus experiencias y encasillamiento como "actor latinoamericano" en la industria española han fomentado su mayor especialización en la dirección de esta compañía. Con ese fin, Carlos ha ido incorporando distintos actores a Entrecalles con quienes ha desarrollado varias obras teatrales. Con estos actores se ha ido articulando dentro de Entrecalles una identidad política de resistencia bajo el signo contingente de latinoamericano. Como pretendo explicar, este signo contingente sirve para unificar experiencias compartidas entre actores latinoamericanos y crear resistencia a la estereotipización de lo latinoamericano. Pero además, sirve para crear unidad frente a la propia racialización diferenciada que se da dentro de lo latinoamericano.

La primera vez que supe de Entrecalles fue a través de un anuncio en la página web de un espacio okupado en Madrid - La Tabacalera- donde se anunciaba la actuación de la compañía como teatro latinoamericano (ver Figura 1). La obra que estaban representando en esos momentos era Moscas y Milagritos, basada en las ex-

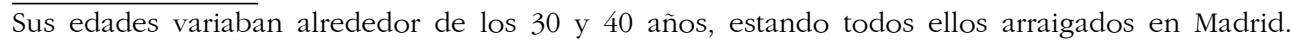
Para el análisis mediático se ha utilizado una variada y extensa fuente de series de televisión, películas, periódicos y prensa minoritaria. En este artículo solo se mencionarán aquellas fuentes objeto de análisis para este trabajo. No obstante, una base de datos importante para investigadoras interesadas en el tratamiento en los medios de las minorías étnicas en España es el Observatorio de Medios de Mugak <http://www.mugak.eu/observatorio-de-medios>. 
periencias de Carlos trabajando con "niños de la calle" en Lima y donde se plasma el día a día y las grandes dificultades de las clases sociales más bajas de Lima por mejorar su situación. En esta obra teatral los actores eran mayoritariamente latinoamericanos - a excepción de una actriz española- lo que favoreció la definición de la compañía y el grupo como teatro latinoamericano. Tras contactar a Carlos, me ofrecí voluntaria para colaborar en la compañía a la vez que realizaba investigación/observación participante. Desde mis primeros momentos con ellos pude observar que esta alta presencia de actores latinoamericanos existía también en sus previas obras. Sin embargo, no pretendo afirmar aquí que la mera existencia de actores de procedencia latinoamericana en la compañía haya directamente creado una identidad compartida, sino que esta se ha ido forjando a través de sus prácticas culturales y la puesta en común de experiencias similares, desembocando en una alianza en torno a, siguiendo a la socióloga Avtar Brah (2011:43), "una experiencia e identidad compartida".

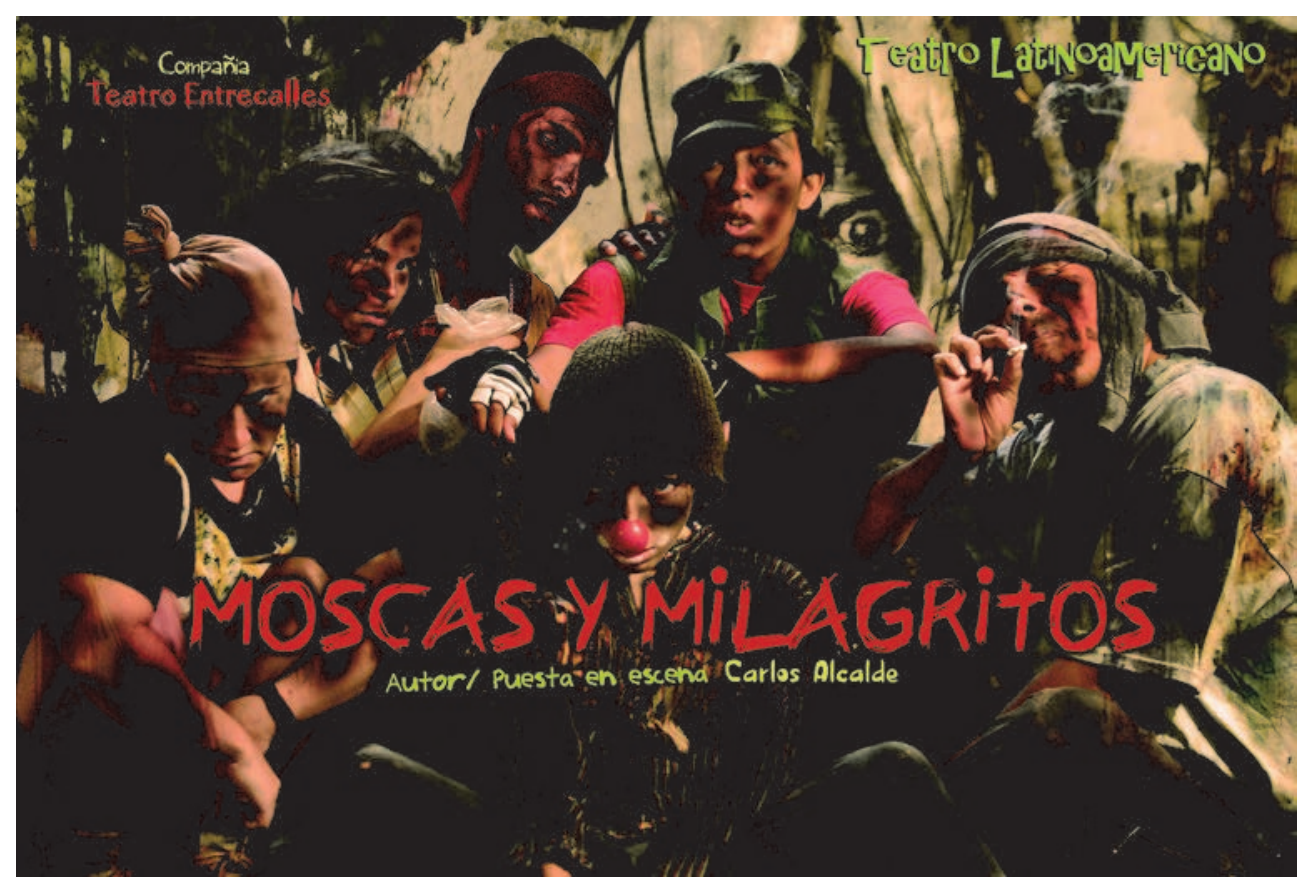

FiguRA 1.-Flyer de la obra Moscas y Milagritos, cedido por Entrecalles.

Una de las actrices de Moscas y Milagritos es Ari, mujer colombiana que llegó a vivir a Madrid a través de una beca de estudios y decidió permanecer en la ciudad tras entablar una relación con un hombre español. Conoció a Carlos durante el casting de un programa televisivo que ambos estaban realizando, donde este le propuso unirse a Entrecalles. Si bien en Bogotá su experiencia como actriz había estado más encaminada a la televisión, en Madrid encontró más oportunidades en el teatro: 
Aquí empecé a presentarme para cortos y no me cogían por el perfil latino, que como no tengo el perfil latino tan marcado... Entonces, la representante que yo tenía me dijo: "Yo te quiero manejar, me encanta tu material, pero el físico es un problema". Entonces me cogió un tiempo, no pudo conmigo, me lo dijo y ya. Un colombiano para nada es un prototipo como el mío. Realmente en Colombia hay de todo. Tú vas a Colombia y no necesariamente es indígena. Hay rostros indígenas, pero hay de todo. Mi hermana es rubia, de ojos claros. O sea que...

Y ahora sí se me está facilitando un poco dentro de la industria. Porque hice una película que la directora me cogió y no le importó mucho el perfil. Afortunadamente le gusté y a partir de esa película me cogió otra representante que me está moviendo. Pero me está moviendo mucho por el teatro. Más que por la tele, porque no hay nada ahora, y aparte porque hasta que no te conocen bien, es difícil entrar así como latina de perfil tan marcado (Ari, actriz de Entrecalles, entrevista personal, 28 ago. 2013).

Las experiencias de Ari y Carlos marcan similitudes en cuanto al encasillamiento en un "perfil latino", sin embargo, existen diferencias en cuanto a cómo cada uno de ellos cumplen características físicas que corresponden al perfil. Siendo Carlos de ascendencia quechua es, entre todos los actores que conocí en Entrecalles, quien más cumplía el rol de lo latino y quien más éxito había tenido en la industria fílmica y televisiva. El "perfil latino" que alude Ari así como "el indígena tapa-rabos" que refería Carlos, ofrecen pistas para entender que los roles de latinoamericanos están dominados por una diferenciación racial de sus cuerpos. Esto responde a una cosificación racialmente diferenciada con anclaje colonial en base al mestizaje ocurrido en América Latina tras la colonización española, que dio lugar a diferentes categorías raciales —indio/indigena, mestizo, mulato, negro- redefinidas ahora en el contexto mediático y cultural español.

Cuando me uní a la compañía, Carlos trabajaba en una serie de televisión de alta audiencia — La que se avecina - en el rol de indio-latino inmigrante sin papeles. Su caracterización en esta serie parodiaba a un pobre indígena colombiano víctima del abuso de su jefe español por su posición inmigrante y, significativamente, situación ilegal en el país. En esta serie Carlos presentaba una imagen muy distante a la que él es o la que representaba en las obras de Entrecalles. Su personaje mostraba subordinación y remarcaba la ilegalidad y condiciones de vida de un latinoamericano inmigrante sin papeles. Este papel reúne características muy similares a las de otra serie española de alta audiencia - Aida - en la que un actor español de ascendencia japonesa interpreta un similar rol denominado Machu Picchu. Al igual que Carlos, este actor presenta características físicas que corresponden al prototipo de inmigrante indio-latino. Similar a Carlos también, este actor representa a un sujeto pasivo quien, hasta después de varias temporadas en emisión, prácticamente no alza una voz de protesta frente al abuso de su jefe español ultraconservador o incluso no tiene un nombre real. Esta imagen y el nombre de Machu Picchu han adquirido gran eco dentro de la sociedad española hasta el punto que el término Machu Picchu es reproducido para aludir — a menudo de manera peyorativa - a personas de similares características físicas y procedencia latinoamericana. Aunque Carlos no es colombiano y el actor de la serie Aida no es latinoamericano, los dos encarnan el rol de inmigrante indio-latino en España.

Otro tipo de roles en los que Carlos ha trabajado corresponden a sicario colombiano, traficante latino, o a papeles en los que simplemente era denominado como 
indio donde mantenía prácticas ancestrales de algún país latinoamericano. Entre estos, Carlos interpretó en la serie Carlos, Rey Emperador - basado en la vida de uno de los emperadores más poderosos de la colonización española en América- el rol de azteca que entra en contacto con los colonizadores españoles en México y se muestra estupefacto al ver la avanzada tecnología de los colonizadores. Este tipo de roles están corporalmente marcados con unas características físicas y neo-primitivistas que construyen la imagen de indio inmigrante en el contexto actual español o el de indígena en la antigua colonia, para lo cual, la evidencia física de la ascendencia quechua de Carlos resulta más idónea que la de Ari. Pero además, estos roles están fuertemente vinculados a una serie de discursos inscritos en las narrativas fílmicas, ya sea sobre episodios coloniales o sobre inmigración - donde lo español se representa repetidamente como superior y carente de mestizaje - frente a lo latinoamericano - racialmente diferenciado-.

Para profundizar en la raíz colonial de dichas narrativas, me sirvo del concepto que ofrece la académica Diana Taylor de theatricality. Taylor usa theatricality para explicar los "encuentros teatrales" que surgieron tras la llegada de Colón a las Américas y las consiguientes interpretaciones del "cuerpo de los nativos" en los textos de expertos (lingüistas, científicos, etnógrafos y cartógrafos) que llegaron con y tras los colonizadores. Siguiendo a Gayatri C. Spivak (1993), la autora desvela que esta relación interpretativa posiciona a dichos nativos dentro de un discurso colonial que produce al nativo como negativo o carente de voz para hablar (Taylor 1998: 162). Así, theatricality responde a estructuras estéticas, políticas y perspectivas dentro de las cuales los caracteres están posicionados e interpretan roles prescritos. Theatricality es pues "un nombre sin verbo y por lo tanto sin posibilidad de posición del sujeto" (1998: 161). Extrapolando esta idea al contexto en el que se desarrolla este artículo, vemos cómo las representaciones de sicarios, indios-latinos o inmigrantes latinoamericanos nos muestran predominantemente una visión postcolonial en la que el cuerpo de los nativos - ahora en la ex-metrópolis - son vistos y descritos desde la perspectiva del descubridor — ahora la sociedad receptora a través de la escena visual-. Y que además, muestran una ilusoria supremacía española bajo narrativas donde el indio colonizado o inmigrante latino está vencido, marginalizado, victimizado o criminalizado frente al español. La repetición de este tipo de roles y narrativas dentro de películas y series de televisión es lo que lleva a Carlos a afirmar que "no me van a llamar por mis cualidades interpretativas", a lo que añade "a pesar de que claramente parezco peruano, pero me llaman para hacer de colombiano, mexicano... como si todos nosotros pareciéramos iguales".

El resto de actores de Entrecalles, así como otros actores latinoamericanos con los que pude hablar (a los que conocí a través de algún miembro de Entrecalles), expresaron similares experiencias a la de Ari. Entre ellos, Rodrigo Villagrán, un actor chileno amigo de la actriz de Entrecalles Lula, quien ofrece información que explica cómo otros marcadores como el lingüístico se articulan con la apariencia física en la representación de lo latinoamericano:

Esta gente [industria fílmica] han determinado los caminos que he tomado en mi carrera profesional. Estoy más y más asentado en España. Mi pareja es de aquí, así que si quiero quedarme aquí tengo que probar que puedo hacer cualquier rol eliminando el acento latinoamericano. Y mi perfil no es uno fácil, porque soy latinoamericano, pero no el lati- 
noamericano que esta gente busca. Soy algo entre medias. No soy español, pero sueno como latinoamericano... Y aquí, en España, no existen muchas narrativas en las que puedo encajar.

Dejé de trabajar con mi agente porque en tres años ella solo me consiguió tres series de televisión. Mis roles eran: líder de una banda de traficantes colombianos en la serie Hospital Central; uno similar en la serie Barco y en el otro un empresario colombiano que es secuestrado. Así que ése es mi perfil, porque no puedo hacer el Machu Picchu de la serie Aída, por ejemplo. Así que si tengo que eliminar mi acento para ser capaz de trabajar en este país, lo haré (Rodrigo Villagrán, actor, entrevista personal, 8 jul. 2013 ).

La paradoja de la construcción de roles latinoamericanos es que la cosificación racial de estos actores actúa simultáneamente de manera homogénea y diferenciada. Es decir, actúa como homogénea en la medida en que personas como Carlos — de ascendencia quechua - resultan idóneas para el rol de indio-latino indiferentemente del país latinoamericano al que se aluda. Sin embargo, actúa de manera diferenciada en la medida en que actrices como Ari o Rodrigo no responden a estereotipos físicos para roles de latinoamericanos y el lingüístico/acento actúa como determinante para poder realizar roles españoles. Como argumento, desde tiempos coloniales, las poblaciones latinoamericanas han sido diferenciadas entre ellas mismas en función de su mestizaje. Se ha insistido en explicar desde distintos trabajos sobre colonialidad (Grosfoguel 2006; Quijano 2000; Quintero 2010; Stolcke 2009) que figuras como la de indio, negro, mestizo y mulato se constituyeron como categorías sociales y jurídicas tras la colonización de las Américas y fueron acentuadas como raciales desde el surgimiento del racismo moderno en el siglo XVIII. Aunque estas categorías han sido cambiantes y han transmutado a lo largo de la historia y el espacio (ver Cadena 2005), el mestizaje que se originó tras estos encuentros dio lugar a categorías distintas sobre la cual se asentó una ideología racial basada en la diferenciación. La socióloga Avtar Brah (2011: 26) analiza cómo estas diferenciaciones vienen al presente, y señala que los cuerpos de los sujetos o grupos étnicos que son racializados, además son diferenciados entre ellos mismos de manera jerárquicamente configurada bajo una "racialización diferencial". Es decir, las diferencias raciales no actúan simplemente bajo relaciones dominante $v s$. dominado, sino que los grupos que son racialmente diferenciados son también posicionados de manera diferente entre ellos mismos en base a dichos procesos históricos de mestizaje. En el contexto mediático español en el que se basa esta investigación, esto se traduce en una rápida clasificación de cuerpos indígenas, mientras que posiciones mestizas resultan —siguiendo a bell hooks (2015) y Suki Ali (2004: 84)— «inteligibles e imposible de articular de otra manera que no sea a través de una lista de factores que incluyen la raza, nacionalidad y ascendencia".

Bajo estas experiencias compartidas y a la vez diferenciadas, actrices y actores latinoamericanos se han agregado dentro de Entrecalles como un espacio donde crean unidad y además se construyen narrativas que superan estas y otras diferencias. En España es donde, como Carlos me dijo, se vio a sí mismo por primera vez como actor latinoamericano haciendo papeles de latinoamericano, y donde conoció a otros actores como Ari y Rodrigo que compartían similares experiencias, con quienes se identifica bajo el signo contingente de teatro latinoamericano. Veremos ahora la incorporación de actores de otras procedencias a la compañía y la influencia que ejercen para que se re-articulen hacia el signo contingente de inmigrante. 


\section{MANIFIESTO CONTRA EL TRATAMIENTO A LATINOAMERICANOS Y AFRICANOS}

En esta sección explico dos formas de cohesión entre actores latinoamericanos de Entrecalles y actores de procedencia africana. Una de ellas ocurre cuando actores de Entrecalles conocen a actores africanos de países subsaharianos: encuentran que sus experiencias son compartidas por estos y piensan en escribir un manifiesto conjunto como protesta. La otra sucede tras la incorporación de actores africanos marroquíes a la compañía, de tal forma que, Entrecalles, que inicialmente se identificaba en Madrid como teatro latinoamericano, paulatinamente comienza a tener un discurso donde inmigrante actúa como signo contingente frente a la división nacional/inmigrante. En ambos casos, actores de todas estas procedencias aparecen bajo un extrañamiento frente a lo nacional en narrativas que les encasillan y perpetúan como inmigrantes.

Al poco tiempo de incorporarme a Entrecalles, la obra Moscas y Milagritos finalizó su andadura, mientras se ponía en marcha una nueva obra —El Polvo de mis Huesos- basada en distintos procesos migratorios y coloniales con un especial hincapié en la relación América Latina-España y las disputas entre diversas civilizaciones por el control de la península ibérica desde la Edad Antigua. De nuevo la presencia de actores para esta obra era en gran parte latinoamericana, compuesta por el propio Carlos, Marcelo Galván —mexicano—, María González —mexicana—, Juliana Ascúa — argentina—, José Fuentetaja —español—y Ben Zahra —marroquí-; además del técnico de sonido Nicolás Luzzi —argentino—y Miguel Arenas —un colaborador de visuales chileno-. Más tarde se incorporarían la actriz española Lula Castellanos, quien sustituyó a María tras volver a su país, y Zohra Hichau, española de ascendencia marroquí que sustituyó a Juliana por los mismos motivos. Como Carlos me contó, sus propias vivencias migratorias marcaron la escritura del guión para esta obra, y buscó expresar otras experiencias migratorias desde actores de varias procedencias:

Consideré que los actores tenían que ser de diferentes rasgos étnicos. Entonces mi ideal de este montaje era tener un africano, un asiático... Diferentes razas que vayan a contar eso. No lo conseguí porque actores asiáticos no encontraba con facilidad. Encontré dos y no podían porque estaban en otras cosas. Para encontrar también una actriz africana o un actor africano era también complicado, porque todo el mundo estaba como liado. Es muy difícil conseguir los tiempos, que sus tiempos se ajusten a los míos. Y al final, pasaba el tiempo y decidí el elenco que más o menos hay ahora (Carlos Alcalde, director de Entrecalles, entrevista personal, 11 mar. 2013).

En esta búsqueda de actores por distintos espacios artísticos de la ciudad de Madrid, Carlos conoció a Sari Bibang, una actriz española y ecuatoguineana. Este primer acercamiento a actrices de ascendencia africana por motivos artísticos le permitió conocer similares reclamos por parte de estos con respecto a sus posiciones en la industria fílmica española. Pero además, los encuentros dieron pie a conocer que ambos grupos habían tenido la misma idea de redactar un manifiesto al respecto. Carlos me habló de este manifiesto a la vez que me sugirió conocer a Sari facilitando su contacto. Llamé a Sari por teléfono y acordamos una cita para realizar una entrevista. Al momento de conocernos Sari rápidamente me preguntó qué tipo de persona esperaba conocer y qué pensé de su acento cuando hablamos por teléfono. Admití que su acento no sonó "africano" para mí. "Lo sé. Mucha gente en España no sabe siquie- 
ra que Guinea Ecuatorial fue una colonia española y que hablamos español ${ }^{4}$, , me dijo. En las siguientes horas que estuvimos conversando, mostró muy similares respuestas a las de actores latinoamericanos de Entrecalles, pero ahora desde una perspectiva -e identidad - africana y negra:

Mis roles son: prostituta o marginalizada, o la novia de alguien que me acepta "como soy"; es decir, ¡negra, prostituta y marginalizada! (risas). En cualquier caso, si hago un papel fuera de ese ámbito, siempre existe la necesidad dentro de la industria de justificar por qué estoy ahí. Es decir, si hago un rol de recepcionista en una película, muy probablemente el guión incluirá una justificación de por qué esa mujer negra ha conseguido llegar a recepcionista (Sari Bibang, actriz de la Asociación de Actores Afrodescendientes, entrevista personal, 1 oct. 2013).

Similar a Carlos con respecto a actores latinoamericanos, Sari encontró a otros actores de procedencia africana con quienes fundó la Asociación de Actores Afrodescendientes:

Cada vez que me encontraba con actores de la raza negra..., incluso actores de otros países. Hablo de la raza negra porque su problemática es lo que conozco, pero al final todos lidiamos con lo mismo. Así que la idea de la asociación surgió porque cada vez que actores afrodescendientes nos encontrábamos nos dábamos cuenta de que teníamos el mismo problema. Aunque también existen diferencias entre ser un actor negro y una actriz negra. Ellos tienen un poco más de variedad que las mujeres negras. Por ejemplo: un actor negro puede hacer de portero y ése no es un "rol humillante". No considero que todos los roles de prostituta que he hecho me hayan degradado. Ninguno de esos roles estaban centrados en el hecho de que era prostituta..., pero ese era el rol. En la mayoría de las películas o trabajos que he hecho he tenido que proyectar un acento. Como puedes ver tengo un acento español neutral. En todos los trabajos he proyectado un acento extranjero; africano. Porque están "vendiendo" a una chica sin recursos que es prostituta. ¡Una chica que no tiene recursos y es prostituta no puede hablar correctamente como yo lo hago! (Sari Bibang, actriz de la Asociación de Actores Afrodescendientes, entrevista personal, 1 oct. 2013).

Roles de trabajadoras del sexo son normalmente representados en producciones fílmicas por mujeres o personas transgénero cuyos cuerpos están sexualizados de una manera racial. Es importante señalar la articulación de género y sexualidad con racismo en este tipo de representaciones de mujeres negras africanas, a menudo compartido con latinoamericanas. El problema no es solo que las oportunidades que Sari encuentra para trabajar en la industria cultural están centradas en esta articulación de lo sexual y lo racial en la figura de mujer prostituta, sino que además responde a una representación histórica colonial del cuerpo sexualizado de mujeres negras. Como sostiene Montserrat Alás Brun, España ha mantenido un concepto de "otro tropical" sobre hispanoafricanos, afrocubanos y africanos negros en general en narrativas de cine, literatura y teatro (Alás-Brun 2006 y 2004). Este "otro tropical" nace en Europa de la moda exótica y primitivista de principios del siglo XX que mantiene una postura idealizadora del "otro racial" y en España se combina con una actitud condescendiente y a menudo

${ }^{4}$ A pesar de que el país fue colonia española hasta 1968 y la presencia ecuatoguineana es una de las de mayor arraigo africano en España, existe un alto desconocimiento sobre ello. Algunos trabajos sobre Guinea Ecuatorial pueden encontrarse en: Almazán (2015), Aranzandi y Moreno (2013), Nerín (1998) y Ndongo-Bidyogo (2014). 
racista hacia las personas negras en general y africanos de la región subsahariana en particular (Alás-Brun 2006: 429). Esto además se acentúa con una postura colonialista e imperialista del gobierno español —exacerbada durante la dictadura franquista con especial hincapié en la todavía colonia española de Guinea Ecuatorial (Alás-Brun 2004)—, que a través de distintas formas artísticas utiliza tópicos que condicionan la percepción del público español en torno a unos clichés sexualizados y racializados. Como sostiene la antropóloga Lourdes Méndez, la «ideología sexual que impera en el terreno artístico es una de las más difíciles de desenmascarar" (Méndez 1995: 104; también Méndez 2004 y 2006), siendo mujeres africanas y negras unas de las que más han sido expuestas y asociadas desde tiempos coloniales con lo exótico, el desnudo "primitivo" y otras formas asociadas con la sexualidad.

Las experiencias de Sari marcaron su deseo de fundar, junto a otros actores de procedencia africana, la Asociación de Actores Afrodescendientes. Aunque los roles africanos tienen unos matices propios, comparten con latinoamericanos su posición secundaria, peyorativa y silenciada. Estas similitudes llevaron a Sari y a Carlos a pensar en escribir el mencionado manifiesto que no pudo llevarse a cabo, como ambos me explicaron:

Queríamos que todo el mundo en la industria firmara el manifiesto. El manifiesto diría que los roles de africanos y latinoamericanos están muy marcados por los fenotipos que tenemos. Que hay una discriminación ahí. Pero al final no lo hicimos. Ahora hay un grupo de actores africanos que también quieren hacerlo. Pero también tuvimos esa idea nosotros. Y les he dicho que sería mejor si lo hacemos conjuntamente, para tener más fuerza (Carlos Alcalde, director de Entrecalles, entrevista personal, 8 jul. 2013).

Es cierto que existe un nexo entre nosotros, pero nunca he sido llamada para hacer de aborigen. No sé cómo se sienten cuando son llamados para roles de aborígenes cuando están viviendo aquí desde hace 800 años; o cuando puedes hacer muchas otras cosas. Así que eso me hace sentir que no tengo la capacidad de empatizar con ese problema específico. Y creo que es muy importante ser capaz de empatizar con los miembros de tu asociación. Por eso es por lo que decidimos hacer la asociación de afrodescendientes. Esto no significa en absoluto que no podamos encontrarnos en el futuro con latinoamericanos y trabajar en temas conjuntos. Porque estoy segura de que hay muchos (Sari Bibang, actriz de la Asociación de Actores Afrodescendientes, entrevista personal, 1 oct. 2013).

Lo que esto nos sugiere es que a pesar de las similitudes que existan en las representaciones de africanos subsaharianos y latinoamericanos, es importante notar que, como Avtar Brah (2011: 122) señala, en las sociedades europeas contemporáneas hay distintas formas de racismo viviendo conjuntamente, las cuales operan articuladamente con muchos marcadores distintos como el sexual o la clase social. Pero además, para que una identidad de resistencia pueda ser articulada es necesario un link que actúe como signo contingente entre distintos sujetos. Stuart Hall (1986: 53) sugiere que es necesario preguntarnos por qué elementos ideológicos bajo determinadas condicionen se agrupan dentro de un mismo discurso y cómo y por qué no se articulan en otras condiciones. Para entenderlo podemos comparar esta etnografía con el trabajo de Avtar Brah, que muestra que en el contexto de Gran Bretaña afro-descendientes y sud-asiáticos han articulado una identidad política bajo el signo contingente de Black. Brah claramente explica que esto se debe a que ambos grupos son etiquetados en discursos racistas británicos como negros. Sin embargo, no existiría tal correlación en España, ya que la historia racista sobre africanos y latinoamericanos ha sido etiqueta- 
da de manera distinta, siendo lo latinoamericano una inclusión de diversas etiquetas donde lo mestizo, negro, indígena y mulato se articulan y desarticulan en distintos contextos diaspóricos. No obstante, los encuentros entre Sari y Carlos así como el trabajo conjunto de artistas latinoamericanos y africanos siguen ocurriendo en diferentes espacios culturales de Madrid'5.

Lo más destacable en este hecho no es tanto que el manifiesto se consolidara o no, sino que ambos grupos están presentando las mismas preocupaciones y dificultades y qué es lo que esto nos dice de la industria cultural y mediática en España. Xavier Ruiz Collantes et. al. (2006: 113) hace un análisis sobre la representación que de inmigrantes se da en series televisivas españolas y catalanas, donde resalta la "elevada frecuencia con que se retrata a los inmigrantes como personajes con algún tipo de problema o carencia relevante que un español debe resolver". Destacan además que gran parte de estas representaciones han estado centradas en latinoamericanos y en menor medida africanos (aunque mayor en africanos subsaharianos que magrebíes), donde los latinoamericanos son predominantemente presentados como "seductores, extrovertidos y en menor medida liantes" y africanos "fundamentalmente liantes" (2006: 110). Sostienen los autores que la relevancia de estas representaciones trasciende también al hecho de que los valores subyacentes de los mensajes transmitidos tienen un gran eco con respecto a la construcción de los imaginarios en nuestra sociedad alrededor de estos grupos (2011: 121). Aunque no me extenderé en ello, es necesario señalar que gran parte de estas representaciones tienen su correlativo en los medios de comunicación como extensivamente han demostrado diversas investigaciones (Dijk 2005; Gifreu 2006; Suárez y Ferrández 2012). En concreto el antropólogo Peio Aierbe (2003), señala que España ha pasado de ser el país europeo con mayor aceptación a la inmigración según recogen diversos estudios hasta 2002, fecha a partir de la cual la situación ha empeorado debido al énfasis dado por partidos políticos, y su reflejo en los medios de comunicación, hacia temas migratorios asociados con delincuencia y conflicto.

Así pues, vemos que existe un contexto mediático propicio a la idea de inmigrante como problemática frente a lo español, que se enfatiza con cuerpos racialmente y sexualmente marcados. Pero además, hemos de resaltar la vulnerabilidad con la que determinadas procedencias de países africanos y latinoamericanos tienen hacia la clasificación como inmigrantes, que entiendo guarda una relación con cómo la idea de raza sigue operando hoy en día. En este sentido, el filósofo camerunés Achile Mbembe (2016: 275) señala que las herencias de la colonización anteriormente explicadas no han sido liquidadas, sino que estas operan a través de legislaciones de antiextranjeros en Europa que "hunden sus raíces en una ideología de la selección entre las diferentes especies humanas que, mal que bien, se intenta enmascarar". De manera similar, la antropóloga Verena Stolcke (1995) sostiene que en las últimas décadas en los países europeos, el racismo ha transmutado hacia un fundamentalismo cultural donde sujetos de antiguas colonias y países considerados inferiores son cultural-

\footnotetext{
${ }^{5}$ Ver por ejemplo el trabajo de Carlos con los actores senegaleses Ibrahima Diop, Badara Bam y Leah Katheu en Un millón de sandias (Alcalde 2015); el trabajo de Marcelo Galván con el cantante de rap ecuatoguineano Derico Classic (2015) y la ya mencionada puesta en conjunto de artistas de distintas procedencias en la noticia cabecera de este artículo (Gutiérrez 2017).
} 
mente diferenciados y vistos como extraños al estado, lo nacional y la política. Este fundamentalismo cultural les segrega y reduce su participación en diversas esferas de la sociedad. Cabe pues cuestionarnos si las representaciones de latinoamericanos y africanos están contribuyendo a la vulnerabilidad con la que en el imaginario colectivo se asocia la idea de inmigrante con africanos y latinoamericanos —independientemente del arraigo en el país- y de qué manera esta etiqueta es beredada por sus descendientes.

Como respuesta, dentro de Entrecalles y con la obra El Polvo de mis Huesos - dedicada a procesos migratorios- el grupo comienza a re-articular un discurso sobre la posición de inmigrante. Aunque todos los actores que se incorporan a Entrecalles tienen un interés artístico y profesional, también se mostraron partidarios de este discurso. Jose - madrileño- y Lula — asturiana - se mostraron contrarios, como ambos me expresaron, a estas formas discriminatorias con población migrada en España. En el caso de Ben, de procedencia marroquí, y más tarde Zohra hija de marroquíes en España, está señalando otros caminos de etiqueta racial en España:

Nosotros, los actores marroquíes, no somos considerados actores. La "industria" es un mundo de paletos. ¡Sí! El mundo de la industria fílmica española, la manera en la que ellos tratan a los inmigrantes..., son auténticos paletos. Porque las películas y la televisión no reflejan la realidad. Al menos que seas cubano o argentino..., por su trayectoria. Pero un africano, un marroquí, un argelino, no nos ven como actores; nos ven como mano de obra barata. Por ejemplo, una película que habla sobre marroquíes y argelinos, ¡no nos contratan! Contratan a españoles con fenotipos árabes. Y si tienen que hablar árabe traducen la fonética a palabras latinas y las aprenden. En lugar de trabajar con nosotros. No confían en nosotros y nuestro trabajo es mostrarles lo contrario. Lo estamos mostrando y no hay trabajo para nosotros. Solo nos llaman para hacer de traficante, terrorista o violador. Me gustaría ver una película que hable sobre amigos, ¿no? Tú no ves ningún español que tenga un amigo extranjero en una película. A lo mejor ponen una persona negra en la última fila de un bar. En la serie Toledo ${ }^{6}$ no trabajan actores marroquíes. Ponen mujeres rubias, guapas con el pelo rubio y liso que hacen de marroquíes (Ben, actor de Entrecalles, entrevista personal, 2 may. 2013).

Desde el suceso del 11S en Nueva York y, más tarde, los atentados de Atocha en Madrid el $11 \mathrm{M}$, se ha acentuado una imagen de terrorismo islamista en los medios de comunicación hacia personas magrebíes o de ascendencia árabe (García Sanjuán 2016). Esto ha favorecido que la etiqueta racial de actores de procedencia árabe se asociara con un cariz religioso y vinculación al terrorismo, con unos matices también claramente diferenciados a los de latinoamericanos. Sin embargo, como podemos ver en las palabras de Ben en su alusión al tratamiento en la industria fílmica de inmigrantes, su experiencia como actor marroquí se unió dentro de Entrecalles a la de otros actores en El Polvo de mis Huesos bajo un discurso de experiencias compartidas como inmigrantes. Así, si bien para la obra anterior la compañía se anunciaba como teatro latinoamericano, El Polvo de mis Huesos se denomina y anuncia como "obra sobre las migraciones" (ver Figura 2).

\footnotetext{
${ }^{6}$ Serie española de televisión Toledo, cruce de destinos que reproduce los tiempos de luchas entre cristianos y musulmanes por el control de la península ibérica en el siglo XIII.
} 


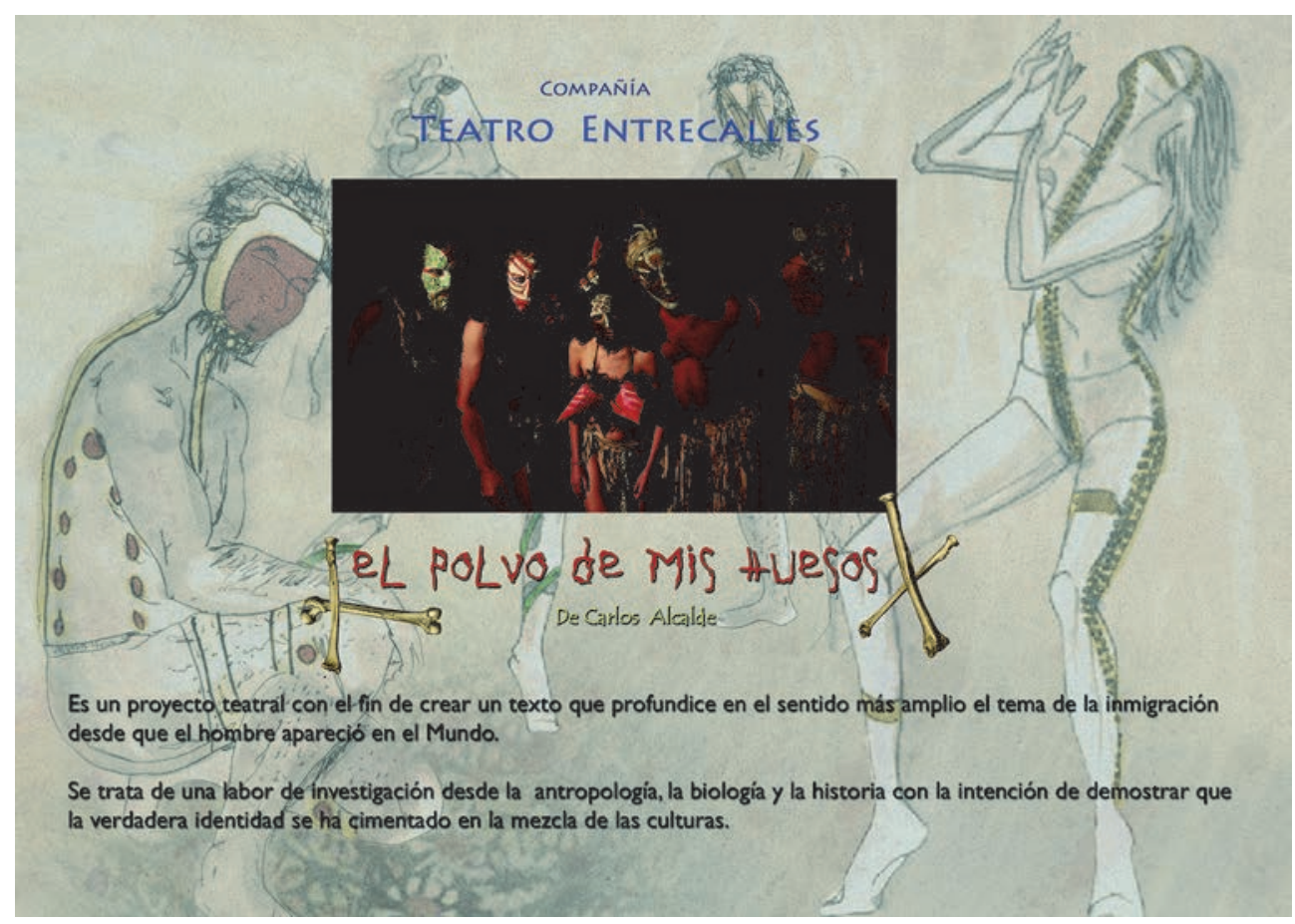

Figura 2.-Dossier de la obra El Polvo de mis Huesos, cedido por Entrecalles.

No obstante, las palabras de Ben nos están mostrando otros caminos a analizar. Su alusión al uso de actores españoles para roles de musulmanes correspondería a lo que en la industria de Estados Unidos se denomina whitewashing; es decir, el uso de actores blancos para personajes de otros grupos étnicos ${ }^{7}$. Esto está motivado por el hecho de que su profesionalidad se encuentra infravalorada. Sostiene Liliana Suárez en su análisis de espacios mediáticos, que para abordar críticamente la herencia racial y colonial que de forma diversa experimentan profesionales inmigrados a España, es necesario ver cómo las empresas mediáticas y las industrias culturales excluyen laboralmente a inmigrados cualificados (Suárez 2011: 255). Lo que a su vez, nos está permitiendo visualizar el tipo de cultura política desde la que se construye el modelo de ciudadanía (2011: 254). Si bien las experiencias de Ben, Sari, Carlos, Rodrigo y Ari nos está describiendo un contexto en el que su profesionalidad está infravalorada o relegada a un segundo grado de importancia y juegan papeles inferiorizados frente a lo nacional, es aquí donde debemos cuestionarnos también el tipo de cultura política desde la que se ha construido lo español. Como sostengo, la repetitiva representación racializada de lo inmigrante nos está hablando de una tendencia histórica e

\footnotetext{
${ }^{7}$ Montserrat Alás-Brun (2004) señala que a lo largo de la historia en películas y obras de teatro españolas se han utilizado actores no negros que se pintaban el cuerpo para hacer "roles de negros". Igualmente, existen fuertes críticas a la festividad de los Reyes Magos en España, donde con frecuencia se repite este hecho para interpretar el papel del rey negro: Baltasar.
} 
institucional de construir lo español excluyendo a minorías étnicas o mestizajes. Profundizaremos ahora en esta enraizada tendencia por la que personas de procedencias latinoamericanas, africanas de zonas subsaharianas o africanas de zonas magrebíes actúan bajo etiquetas raciales excluidas en lo español.

\section{EL ILUSORIO BLANQUEAMIENTO DE LO ESPAÑOL}

Para explicar el efecto blanqueador que provoca la exclusión de minorías étnicas de la idea de lo español, hago un alto en la etnografía y me sirvo de trabajos con cariz historiográfico que sugieren que las culturas políticas en España, a lo largo de su historia, han tendido a olvidar o descuidar la presencia e influencia que han tenido y tienen grupos étnicos considerados como Otros en el país. El historiador Alejandro García Sanjuán (2016: 2) explica que la época histórica así llamada de Reconquista - en la que cristianos y musulmanes se disputaban el control de la península ibérica- es utilizada tanto por políticos, medios de comunicación y la academia para exaltar una identidad española cristiana excluyendo a al-Andalus - y de aquí lo musulmán e islámico- de la identidad nacional. Es la Reconquista un símbolo sobre el que se ha construido la idea de España como nación, bajo la cual se creó unidad cristiana frente a otras religiones y civilizaciones en el país. En este proceso, señala García Sanjuán, también han sido apartados de lo español judíos sefardíes que fueron expulsados tras la Reconquista, y no es hasta recientemente cuando comienzan a tener un reconocimiento histórico y jurídico en España. Sostiene además el autor que el énfasis del nacionalismo español — acentuado durante la dictadura de Franco- ha girado en torno a una idea de país vinculada a civilizaciones cristianas, donde han primado las figuras y prácticas culturales que conmemoran la presencia cristiana/ visigoda y de reinos cristianos como los de Castilla, Navarra y Aragón por encima de la presencia de otras civilizaciones en el país. Podemos añadir como ejemplo el actual escudo de la bandera española, integrado con elementos y cuarteles de los reinos cristianos de Castilla, León, Aragón, Navarra y Granada.

Remontándonos al trabajo de la antropóloga Christiane Stallaert (1998), encontramos un análisis de esta etnogénesis de lo español que la autora explica a través del casticismo desarrollado en España desde los siglos XII y XIII. Es el casticismo un proceso por el cual la etnicidad española se ha construido a partir de la Reconquista como un "ser cristiano" en oposición principalmente "al moro", pero también frente "al judío". Es asimismo la distintividad étnica sobre la que se basa el nacionalismo español, así como en la que se basarán los nacionalismos periféricos de España posteriormente. Como señala la autora, etimológicamente nación es "sinónimo de linaje o grupo étnico", que en el caso de España se empieza a gestar tras la separación por castas de "judíos", "moros" y "cristianos". La casta a su vez es sinónimo de nación y raza, y el castizo sería el linaje étnicamente limpio frente a la sangre mora o judía. Es por tanto el casticismo una pureza étnico-religiosa que se traduce en un cristiano biológicamente puro cuya sangre carece de contacto musulmán o judío (Stallaert 1998: 22-23). Una manera de confirmar y preservar esta cristiandad pura será a través de apellidos godos, así como políticas de segregación (limpieza de sangre) y posteriormente la expulsión de judíos y moriscos. El máximo exponente de este cas- 
ticismo es reconocido a través de la hidalguía universal que Felipe II concedió a regiones norteñas por la política inmigratoria restrictiva que zonas como Guipúzcoa y Vizcaya habían aplicado a sus fronteras y que ayudó a preservar el cristianismo puro frente a invasiones musulmanas (1998: 72-73). Y puesto que la España cristianovieja tenía su peso en el norte y centro de la península, se dio una mayor uniformidad, difusión e imposición progresiva de elementos culturales, usos y costumbres típicamente castellanos (1998: 65-66).

Si bien Christiane Stallaert nos hablaba principalmente de la convivencia de tres castas (judía, mora y cristiana), otros académicos han mostrado la presencia, convivencia y legado cultural de esclavos y libertos africanos negros y, en menor medida, indígenas y mestizos de América en España desde el siglo XV. Los trabajos de Esteban Mira Caballos (2007; Mira et al. 2016), Rocío Periáñez Gómez (2008a y 2008b), José A. Ballesteros Díez (2006) y Aurelia Martín Casares (1997 y 2015; Martín y García 2010) muestran que ambos grupos llegaron a Extremadura y Andalucía a través de los mercados esclavistas de Lisboa y Sevilla desde el siglo XVI, donde se asentaron y formaron parte de su sociedad ${ }^{8}$. En ambos casos constatan la continuada llegada y asentamiento de africanos negros en estas zonas hasta la abolición de la esclavitud africana en España en 1837. Estos trabajos sacan a la luz un pasado hispanoafricano en España que "apenas ha sido de interés en la historiografía española" a pesar de ser España el país europeo "con más esclavos y esclavas de origen subsahariano entre su población” (Martín y García 2010: 1). Además, señalan cómo, tras la abolición de la esclavitud, estos afro-españoles permanecieron en el país:

Dejan de tener su condición de esclavos y pasan a ser personas libres siguiendo en el desempeño de la actividad que desempeñaban antes de su liberación. Yo estoy seguro de que [en] el folklore extremeño y el folklore andaluz hay muchos elementos subsaharianos. [Pero] pasa un poco lo mismo que con todo lo musulmán. Es un poco lo olvidado; los siete siglos esos no se quieren recordar [...]. Evidentemente los negros eran muy apreciados por sus cantes y por sus bailes (Mira Caballos, en Mira et al. 2016).

Esta línea de investigación ya fue abierta y propuesta por el antropólogo cubano Fernando Ortíz (1981 y 1986), quien explicó la influencia que yoruba, congo y otras poblaciones africanas han tenido durante siglos en la música, danza, teatro e instrumentos en el sur de España. Ortiz describió las habilidades de esta población por mantener elementos culturales y traer valores culturales a la sociedad dominante. Demostró además cómo estos afro-españoles tuvieron un rol importante como actores y escritores en lo que es considerado el nacimiento del teatro moderno; es decir, el teatro desarrollado en España durante el Siglo de Oro (1492-1681). Sin embargo, como él explica, su contribución al Siglo de Oro ha sido borrada e ignorada de la historia. Estudios más recientes, como el de Miguel A. Rosales (2016), han continuado mostrando el legado cultural de estos afro-españoles esclavizados en expresiones artísticas como el flamenco. Igualmente, Baltasar Fra Molinero ha ahondado en la presencia y representación de personas negras en el teatro del Siglo de Oro, señalando cómo "el negro" estaba destinado "al silencio, a la negación y a ser borrado"

\footnotetext{
${ }^{8}$ Ver también el trabajo de Restall (2000) que muestra la presencia de colonizadores de procedencia africana negra entre los llegados a América Latina en la época colonial; y de Piqueras (2011) para un análisis amplio de la esclavitud africana en España.
} 
(Fra Molinero 2014: 25). Tal es así que, señala el autor, los museos nacionales de España han trabajado bajo un discurso esencialista que aparta de la memoria y la simbología de la nación a estas personas afro-españolas (2004: 24).

Lo que estos trabajos vienen a destacar es que distintas zonas de España están cultural y genéticamente influenciadas por la presencia de estas sociedades, dejando entrever que España, en el proceso histórico de construcción como nación, ha apartado dicha influencia de la memoria de la propia nación?. Una memoria que en cambio sí recuerda a héroes cristianos a través de abundantes festividades por el país donde a lo sumo se utilizan figuras como la de musulmanes para representar a los derrotados por la Reconquista cristiana ${ }^{10}$. Sostengo que, la repetida erradicación de la memoria de musulmanes, africanos negros, sefardíes..., denota no solo una intención de presentar unidad cristiana nacional, sino la de crear una ilusión blanqueante - carente de mestizaje- en la nación, en la que negros, indígenas, mestizos, musulmanes, sefardíes, gitanos no tienen cabida de otra manera que como minorías étnicas olvidadas, marginadas, expulsadas y sin influencia significativa para el país. Esta tendencia histórica nos lleva a cuestionar cómo en la actualidad las culturas políticas continúan el discurso donde el vencido, el criminal, el otro racial — representado ahora a través de la idea de inmigrante y lo que descienda de él/ella- siguen manteniendo un discurso con efecto blanqueador. Las voces de los actores de esta investigación demuestran que en las producciones artísticas españolas —así como en las mediáticas- lo latinoamericano, lo africano negro y lo africano magrebi — salvo excepciones- no tienen cabida de otra manera que racialmente etiquetados y diferencialmente inferiorizados a lo español; lo cual no solo aparece exento de mestizaje y etiqueta más allá que la de español sino además, racialmente superior a estos dentro de un discurso postcolonial.

Las razas y sus nuevas formas, siguen operando bajo el concepto de inmigrante basado en el fenotipo, lo sexual, lo lingüístico a través de una cosificación y degradación corporal, en la que - siguiendo a Achille Mbembe- el cuerpo es construido como objeto que toma forma de imagen desde la racialización que hunde sus raíces en un encarnizamiento colonial de división, clasificación, jerarquización y diferenciación (Mbembe 2016: 35).

\section{CÓMO SER DE RAZA Y DESCOLONIZAR ESTEREOTIPOS}

Una amiga mía me llamó en 2005. Ella tenía una amiga que trabajaba en una agencia de actores de raza. Cuando ellos quieren a un negro, hindú o marroquí, lo llaman actores de raza. Como a los perros de raza (risas). De hecho, la agencia se llama Derazas o algo así (Ben, actor de Entrecalles, entrevista personal, 2 may. 2013).

\footnotetext{
${ }^{9}$ No obstante la variedad e influencia de civilizaciones en el país es amplia y quedaría por ampliar aquí las relaciones con otros grupos étnicos históricamente marginalizados, como las poblaciones gitanas calé y aborígenes guanches canarios (Santana 1975). En relación a los primeros, es destacable que, debido al interés exótico que se creó en la Europa costumbrista del siglo XIX por el denominado gitanismo, surgió un interés hacia el papel de las poblaciones gitanas en expresiones culturales como el flamenco (González Alcantud 2011).

${ }^{10}$ Como explica García Sanjuán (2016), existen excepciones como la ciudad de Badajoz donde se utilizan símbolos musulmanes y se celebra la fundación de la ciudad por parte de estos.
} 
Al igual que Ben, otros actores a los que entrevisté aseguraron que gracias a esta agencia habían conseguido papeles secundarios dentro de películas y series televisivas españolas. Lo más destacable no es tanto que exista una agencia intentando facilitar trabajos para ellos, sino que ellos estén tan racialmente diferenciados o etiquetados dentro de la industria cultural española y este sea un elemento tan determinante para su participación. Esto ha dado lugar a que los actores aceptaran estos roles a la vez que intentaban contestarlos desde el proyecto que es Entrecalles. En esta última sección pretendo mostrar cómo Entrecalles revierte el significado atribuido en la industria cultural y dotan a los personajes de diferentes significados a través de la obra $E l$ Polvo de mis Huesos. Esto responde a lo que Achille Mbembe (2016: 230-231) describe como la capacidad de disociarse del propio cuerpo, a través de la potencialidad de revertir fragmentos del cuerpo, evitando así su decadencia en la coseidad absoluta. Denomino este proceso como descolonización del cuerpo y de narrativas desarrollado tanto en la puesta en escena de la obra teatral, como durante sus ensayos.

Aunque no me detendré ahora en este hecho —explicado con más extensión en otro trabajo (Montalvo Chaves 2015) — sí quisiera señalar que tanto esta obra de teatro como los otros proyectos teatrales realizados por Entrecalles en España, se han desarrollado en su mayoría fuera de los circuitos convencionales de salas de teatro, de una manera nómada por distintos espacios de la ciudad de Madrid, alrededores y otras ciudades; en casas okupadas, asociaciones de vecinos, la calle, universidades o colegios mayores. De alguna manera, el salirse de los circuitos regulares ha facilitado que Entrecalles rompa, a través de sus propias producciones teatrales, con narrativas y clichés dominantes. La obra de Entrecalles, El Polvo de mis Huesos, está llena de escenas que generan un diálogo ficticio con la colonización española en las Américas, así como muestran la variedad de civilizaciones que han pasado por España, creando una correlación entre esta antigua variedad de civilizaciones y movimientos migratorios con la incorporación de latinoamericanos y africanos a la sociedad española actual. Igualmente, muestra la capacidad de los actores de desarrollar variados roles que van más allá de los clichés de latinoamericanos y africanos. Veamos uno de los fragmentos de esta obra para localizar primeramente las contra-narrativas:

CRISTIANO 1: ¿Dónde están los Reyes Católicos?!

[Los actores seleccionan a dos miembros de la audiencia que harán de los reyes Isabel y Fernando. Suena una trompeta real y los actores se arrodillan ante los reyes seleccionados].

VISIGODO: Estableceremos la monarquía hispánica y nadie cuestionará su poder.

Todos: iiIntegración, integración!!

CRISTIANO 2: ¡Viva la promiscuidad hispana! [los actores le miran enfadados]

CRISTIANO 3: Majestuosísimas majestades, inauguraremos la Santa Sede así legalizaremos la tortura y la usaremos contra todos los que no profesen nuestras creencias.

CRISTIANo 2: ¡Quiero ese trabajo majestades! Tengo experiencia: he mentido, violado, matado, robado y maltratado.

CRISTIANO 4: Majestuosísimas majestades; excelencias; muy cristianas majestades, incrementaremos el poder económico de la alta nobleza.

CRISTIANO 2: ¿Y quiénes son esos?

VISIGODO: Los que son más ricos.

CRISTIANO 2: ¿Y vamos a darles todavía más riqueza?

VIsigodo: Sí. Así serán eternos nobles. 
CRISTIANO 1: Majestuosísimas majestades; excelencias, muy cristianas, apostólicas majestades. Ahora que somos nobles,.. ¿Qué tal el boom de la literatura castellana y la configuración del estado moderno?

CRISTIANO 2: ¡Conquistaremos África! Necesitamos mano de obra barata.

[Las trompetas reales vuelven a sonar y entra Colón]

COLÓn: Mis altezas, vengo a que me firmen el contrato. Mañana mismo voy a descubrimiento de las Indias.

[Extracto de "Escena de los Reyes Católicos"].

El extracto es un ejemplo de cómo las narrativas son descolonizadas y la historia es re-escrita. Habiendo crecido en la sociedad española, una puede darse cuenta de que el tipo de temas discutidos aquí son, de manera general, omitidos en los discursos dominantes. Los discursos dominantes con tendencia conservadora, celebran el gran imperio español donde no se ponía el sol; aquellos con un cariz más progresista, celebran el mestizaje español con otras culturas o cuerpos como los primeros que ocurrieron en la historia de la humanidad. Después de todo, los colonizadores españoles fueron acusados por sus homónimos británicos y franceses de ser incapaces de controlar sus sexualidades con otros cuerpos, descritos en los textos de colonizadores como culturalmente, religiosamente y fenotípicamente inferiores (Morgan 2005; Overmyer 2005). Pero los discursos dominantes omiten los testimonios que nos hablan sobre la objetivización sexual a la que estuvieron sujetos los cuerpos de mujeres indígenas. Como una historia contra-begemónica, el ejemplo de arriba señala distintas formas de subyugación. Así como en otras partes de la obra, la historia — tanto pasada como presente- se presenta a través de la voz y el cuerpo del subyugado. Esto ocurre por medio de un proceso cognitivo que el semiólogo argentino Walter Mignolo (2008) —influenciado por Gloria Anzaldúa (1999)— describe como border thinking o "pensamiento decolonial".

Walter Mignolo toma una perspectiva histórica y señala el siglo XVI como el momento en el que las disciplinas europeas se convirtieron en voces dominantes. Paralelamente a una transformación económica basada en el capital, surgió en Europa un cambio epistemológico que se extendió por todo el mundo a través del racismo ontológico. El racismo ontológico, basado en la concepción renacentista de humanidad, evaluaba y clasificaba a las distintas poblaciones del mundo, justificando así las colonizaciones europeas sobre los no-europeos. El modernismo se desarrolló paralelamente a este colonialismo, designando historias, subjetividades, maneras de vivir y conocimiento. De esta manera, el control del conocimiento quedó en las manos de hombres blancos y cristianos, que eran conservadores en materia de género y sexo. De tal forma que los aparatos cognitivos que emergieron en el modernismo estaban patriarcal y racialmente constituidos (Mignolo 2008: 11), excluyendo las voces de los oprimidos, quienes eran considerados remotos al conocimiento. Desde este momento hasta el presente las esferas disciplinarias con este diseño eurocentrista se denominan a sí mismas como organizadoras y evaluadoras de cualquier disciplina y conocimiento. Ante tal dominación, surge un pensamiento decolonial y respuestas al conocimiento hegemónico. La opción decolonial denuncia la complicidad entre este dominio de control del conocimiento y la subjetividad, en un intento de deslegitimar modelos de pensamiento; los cuales a su vez pueden ir en paralelo a otros pensamientos críticos. Así, Mignolo toma la idea de biopolítica de Michel Foucault (2007) 
para explicar cómo las disciplinas van en paralelo a las políticas de estado de control del cuerpo y generan un conocimiento disciplinario normativo. Cuando estos cuerpos rechazan la disciplina del Estado y la creación de conocimiento que fomenta la creación de sociedades desbloqueadas del Estado moderno y la economía capitalista, surge "el cuerpo-político", que produce conocimiento para decolonizar el "conocimiento y el ser. Los cuerpos que son geopolíticamente formados así como etnoracialmente clasificados por la "colonialidad del conocimiento", desafían dicho conocimiento presentándose a sí mismos en distintas maneras: masculinos, femeninos, queer, heterosexuales, homosexuales, en distintos lenguajes, religiones... Es decir, como sugeríamos siguiendo a Mbembe, rompen con la cosificación absoluta.

Esta aportación de Mignolo me ayuda a explicar cómo Entrecalles decoloniza el conocimiento y el ser: el conocimiento reflejado en las narrativas dominantes que representan a actores latinoamericanos y africanos dentro de unos clichés —a través de lo que podríamos denominar narrativas decoloniales - ; y el ser, aquellos cuerpos etnoracialmente clasificados en las representaciones con discurso colonial y descolonial - a través de lo que podemos llamar cuerpos decoloniales-. Para esta acción decolonial los actores que Carlos ha ido incorporando a la obra —en su mencionado intento de representar distintas razas - son importantes. Los cuerpos de estos actores operan para la transmisión de significados en dos sentidos, que pueden parecer contradictorios pero que son constituidos de manera complementaria: 1) basado en su procedencia, el cuerpo es utilizado para reproducir el binomio rol/cuerpo de las construcciones estereotipadas - ahora- con la intención de proyectar un significado distinto. Para ello es fundamental la existencia de nuevas historias o contra-narrativas. 2) También basado en su procedencia, el cuerpo es utilizado para romper con las etiquetas raciales, intercambiando etnicidades y sexualidades; es decir, rompiendo con la lógica rol/cuerpo que produce modelos esterotipados.

Como en el extracto de más arriba, no existe un único protagonista en toda la obra. Todos los actores son protagonistas e interpretan distintos papeles donde intercambian roles, lo que además muestra sus capacidades de moverse por distintos espectros actorales y más allá de los prototipos. En esta escena, Carlos es quien hace de visigodo; Marcelo y Lula son hombres cristianos; Juliana y Ben, hombres musulmanes que se convierten al catolicismo; y Jose hace de Colón. Sin embargo, en la siguiente escena: Carlos y Lula serán quienes hagan el rol de indígenas cuando Colón llega a las Américas con otros dos colonizadores: Marcelo y Ben. Aunque existe una correlación etnia/rol por la cual Carlos hace de indígena, Ben de árabe y Jose de Colón, estas caracterizaciones están inscritas en narrativas donde el cuerpo político produce el conocimiento con una revisión de la historia colonial española en Latino América.

Esta relación que los actores mantienen con sus cuerpos es lo que les permite romper con una serie de estereotipos, tanto durante la puesta en escena de la obra como en sus ensayos. Lourdes Méndez explica cómo los cánones estéticos forman parte de un sistema de normas sobre el cuerpo que incluye la manera en la que los cuerpos están pensados, percibidos, representados y actuados, en relación a su sexo, raza y clase social. Los sujetos los interiorizan y como resultado estos sistemas organizan las relaciones culturales que ellos tienen con sus cuerpos sobre las que construyen sus subjetividades (Méndez 2004: 61). La subjetividad desde estas experiencias 
ofrece la oportunidad de transcender, romper con, o al menos modificar, los límites que el cuerpo impone (2004: 88). Estos límites son condicionados por una serie de habitus que aparecen de manera inconsciente. El dramaturgo Eugenio Barba (2005: 15) explica que estos habitus inconscientes e inscritos en los cuerpos pueden desaparecer en las actuaciones. Durante las actuaciones, el cuerpo no tiene que respetar "condiciones habituales del uso del cuerpo". El cuerpo es teatralmente "decidido", "vivo" y permite a la escena atraer la atención del espectador hacia los mensajes que son transmitidos (2005: 9). Sin embargo, para conseguir que los actores salieran de estos habitus, Carlos realizaba ejercicios conscientes durante los ensayos de la compañía. En estos ensayos que presencié vi como pasaba un largo tiempo asegurándose de que los actores fueran conscientes de sus cuerpos como clave para construir los roles de la obra. Cuando le pregunté por estas prácticas indicó la importancia que para él radica en el cuerpo:

Los actores trabajan con sus voces y sus cuerpos. Y en muchas ocaciones, en las obras convencionales ves que solo trabajan la voz. Personalmente me gusta construir los personajes desde el cuerpo. Porque el espectador tiene que identificar que hay otro personaje. Tienes que empezar a elaborar tu personaje desde el cuerpo (Carlos Alcalde, director de Entrecalles, entrevista personal, 4 abr. 2013).

En los ensayos de la obra, Carlos dirigía a los actores a tener constancia de sus cuerpos y los movimientos de este. Comenzaban con ejercicios que les permitían desprenderse de los habitus, seguido de otros ejercicios que libremente les ayudaban a expresar sus emociones; para más tarde Carlos guiar los movimientos de sus cuerpos hacia la construcción del personaje, pidiéndole que exteriorizaran emociones asociadas a las narrativas y los personajes. Como la antropóloga Sonia Cajade (2009: 14) explica, a través de ejercicios que mueven el cuerpo y las expresiones corporales, los actores aprenden a ser conscientes de sus cuerpos para construir y hacer vivo el rol que van a interpretar. Si bien esta idea era importante para Carlos, otros actores "necesitaban" interiorizar más esa construcción corporal, que se conseguía a través de la repetición de dichos ejercicios en el comienzo de los ensayos. De tal manera que, tanto los ensayos como la puesta en escena de la obra en sí constituían un ejercicio de decolonización, comenzando por el desprendimiento de ciertos habitus y la construcción corporal de roles. Así, se presentaba a los actores como multipleprotagonistas de sus cuerpos en una obra de teatro alejada de los roles de raza que exigen los circuitos regulares.

\section{CONCLUSIONES}

En los últimos tiempos más y más grupos racialmente diferenciados en distintos puntos de España están alzando voces de protestas contra la reproducción de estereotipos en los medios de comunicación y las industrias culturales. Igualmente, descendientes de africanos, latinoamericanos y asiáticos están reclamando ser vistos como miembros del país más allá de su etiqueta racial. Pero además, la complejidad de la España actual reside en ser un país fragmentado, con zonas geográficas con reclamos políticos nacionales específicos, como por ejemplo Catalunya, y también de per- 
tenencia étnica diferenciada, como por ejemplo Euskadi. Sin embargo, he querido ahondar en la parte del presente y del pasado que, en pro de un ilusorio blanqueamiento de lo español, ha sido y es olvidada en el país, y podríamos añadir, desperdiciada. Con esto quiero enfatizar que bajo las culturas políticas de España, el país no solo sufre un ilusorio blanqueamiento frente a los que se denominan inmigrantes de la época actual, sino también frente al propio pasado del país. Este blanqueamiento es ilusorio o iluso en la medida que, como José González Alcantud explica, en la construcción de las "razas culturales" por parte de las ideologías europeas a partir del siglo XVIII, paralelamente se creó una tensión intraeuropea con la construcción de jerarquías internas (González Alcantud 2011:187) por la que españoles — junto a otros sur-europeos como portugueses - han pasado a ocupar un lugar inferior y no claramente definido como blanco, precisamente por haber sido acusados de un alto mestizaje. Quizás en el intento de probarse a sí misma como nación blanca europea, España ha negado parte de su historia y la ha borrado de su memoria. Una memoria que, no obstante, ha quedado reflejada en las prácticas artísticas y culturales del país, como trabajos de Fernando Ortiz (1981 y 1986) y Miguel A. Rosales (2016) han demostrado, y que seguirá viva en trabajos artísticos como los de Entrecalles, a pesar de su vulnerabilidad de ser diferenciados racialmente y ser una y otra vez representados como inmigrantes.

Argumentó Ortiz que no habrá realmente una cultura nacional hasta que todas las voces de un país sean representadas en sus múltiples formas y variedades; y sugirió que depende de los escritores de guiones — que podríamos extender a directores y quizás la demanda de la audiencia- el reflejar otro tipo de narrativas en las cuales los cuerpos racializados puedan hacer cualquier tipo de rol y trabajar en iguales condiciones que el resto de la población.

\section{BIBLIOGRAFÍA CITADA}

Aierbe, Peio. 2003. "Inmigración: los medios de comunicación, creadores de opinión pública". Revista de Pensamiento Crítico. Disponible en: <http://www.pensamientocritico.org/peiaie1103.htm>. Fecha de acceso: 22 feb. 2018.

Alás-Brun, Montserrat. 2004. "The shattered mirror: colonial discourse and counterdiscourse about Spanish Guinea". Arizona Journal of Hispanic Cultural Studies 8: 163-176.

Alás-Brun, Montserrat. 2006. "El Otro Tropical en el teatro español (1930-1970)". Anales de la literatura española contemporánea 31 (2): 427-463.

Alcalde, Carlos. 2015. Un millón de sandias, Senegal, España: Pimienta Negra. Cortometraje. Disponible en: <http://fibabc.abc.es/videos/millon-sandias-5974.html>. Fecha de acceso: 22 feb. 2018.

Ali, Suki. 2004. "Reading Racialized Bodies: Learning to See Difference", en Helen Thomas y Jamilah Ahmed (eds.), Cultural bodies. Ethnography and theory: 76-97. Oxford: Blackwell.

Almazán Tomás, Víctor D. 2015. "Arte público, poder y colonialismo español en Guinea Ecuatorial. El monumento a Ángel Barrera y Luyando (1915)", en José Antonio Hernández Latas (ed.), El arte público a través de su documentación gráfica y literaria. Homenaje a Manuel García Guatas: 195-213. Zaragoza: Institución Fernando el Católico.

Anzaldúa, Gloria. 1999. Boderlands. La Frontera. The new mestiza. San Francisco: Aunt Lute Books. Aranzadi, Juan y Paz Moreno Feliu (coords.). 2013. Perspectivas antropológicas sobre Guinea Ecuatorial. Madrid: UNED.

Ballesteros Díez, José Antonio. 2006. "Esclavitud en la Extremadura del siglo XVI". Espacio, Tiempo y Forma. Serie IV, Historia Moderna 18-19: 51-70. 
Barba, Eugenio. 2005. The Paper canoe. A guide to theatre anthropology. Londres/Nueva York: Routledge. Brah, Avtar. 2011. Cartografias de la diáspora. Identidades en cuestión. Madrid: Traficantes de Sueños. Cadena, Marisol de la. 2005. "¿Son los mestizos híbridos? Las políticas conceptuales de las identidades híbridas”. Universitas Humanistica 61: 51-84.

Cajade Frías, Sonia. 2009. "Teatro y valores en la cultura contemporánea: Un análisis desde la antropología social y cultural". Prisma Social 3: 1-24.

Classic, Derico. 2015. Ice Coke, Clan The Warriors. Videoclip; Graphic Arts (ed.). Disponible en: <https:// www.youtube.com/watch?v=4cB7Upo4fPs\&feature=youtu.be>. Fecha de acceso: 22 feb. 2018.

Dijk, Teun Adrianus van. 2005. Racism and Discourse in Spain and Latin America. Amsterdam/ Filadelfia: John Benjamins.

Foucault, Michel. 2007. Nacimiento de la biopolítica. Curso en el Collège de France (1978-1979). Buenos Aires: Fondo de Cultura Económica.

Fra Molinero, Baltasar. 2014. "Los negros como figura de negación y diferencia en el teatro barroco". Hipogrifo 2.2: 7-29.

García Sanjuán, Alejandro. 2016. "Rejecting al-Andalus, exalting the Reconquista: historical memory in contemporary Spain". Journal of Medieval Iberian Studies 10: 127-145. doi: <https://doi.org/ 10.1080/17546559.2016.1268263>.

Gifreu, Josep. 2006. "La televisión y la construcción de una imagen pública de la inmigración". Quaderns del CAC 23-24: 3-12.

González Alcantud, José A. 2011. Racismo elegante. De la teoría de las razas culturales a la invisibilidad del racismo cotidiano. Barcelona: Bellaterra.

Grosfoguel, Ramón. 2006. "Actualidad del pensamiento de Césaire: redefinición del sistema-mundo y producción de utopía desde la diferencia colonial", en Aimé Césaire, Discurso sobre el colonialismo: 147-172. Madrid: Akal.

Gutiérrez, Icíar. 2017. "A los actores negros nos obligan a poner acentos de África... ¡si soy de Móstoles!’. eldiario.es 26 feb. Disponible en: <http://www.eldiario.es/desalambre/racismo-cultura-Pilar-Pardo_0_615588682.html>. Fecha de acceso: 22 feb. 2018.

Hall, Stuart. 1986. "On Postmodernism and articulation. An interview with Stuart Hall". Journal of Communication Inquiry, June 10(2): 45-60.

hooks, bell. 2015. Yearning. Race, gender, and cultural politics. Londres/Nueva York: Routledge.

Martín Casares, Aurelia. 1997. "Esclavitud y mentalidad: la población esclava de Granada a lo largo del siglo XVI. Chronica Nova 25: 337-348.

Martín Casares, Aurelia (ed.). 2015. Esclavitud, mestizaje y abolicionismo en los mundos hispánicos. Granada: Editorial Universidad de Granada.

Martín Casares, Aurelia y Margarita García Barranco (comps). 2010. La esclavitud negroafricana en la historia de España. Siglo XVI y XVII. Granada: Editorial Comares.

Mbembe, Achille. 2016. Crítica de la razón negra. Ensayo sobre el racismo contemporáneo. Ulzama: Ned Ediciones.

Méndez, Lourdes. 1995. Antropología de la producción artística. Madrid: Editorial Síntesis.

Méndez, Lourdes. 2004. Cuerpos sexuados y ficciones identitarias. Ideologías sexuales, deconstrucciones feministas y artes visuales. Sevilla: Instituto Andaluz de la Mujer.

Méndez Pérez, Lourdes. 2006. “Quiénes dictan las reglas en el arte? De la primitivización de artes y artistas no occidentales al mutuo reconocimiento: un desafío político y artístico pendiente". Artes. La revista 6(11): 24-34.

Mignolo, Walter D. 2008. "La opción descolonial". Letral 1: 4-22.

Mira Caballos, Esteban. 2007. "Indios y mestizos en la España moderna. Estado de la cuestión". Boletín Americanista 57: 179-198.

Mira, Esteban, Rocío Periáñez, Lui Louireiro, Elena Morán, Juan Llano y Domingo Barbolla. 2016. 52 Minutos: Los últimos esclavos. Documental. Canal Extremadura, Dosde Extremadura Media. Disponible en: <http://www.canalextremadura.es/alacarta/tv/videos/52-minutos-los-ultimos-esclavos-070416>. Fecha de acceso: 26 feb. 2018.

Montalvo Chaves, Ángeles, 2015. "Free Means Libre": Racialization of Arts in Madrid and Latin American Resiliance through Performance.. Transforming Anthropology. Journal of the Association of Black Anthropologists 23(1): 14-26. 
Morgan, Jennifer L. 2005. "Male Travelers, Female Bodies, and the Gendering of Racial Ideology, 1500-1700", en Tony Ballantyne y Antoinette Burton (eds.), Bodies in Contact. Rethinking Colonial Encounters in World History: 54-66. Durham/London: Duke University Press.

Ndongo-Bidyogo, Donato. 2014. Historia y tragedia de Guinea Ecuatorial. Selección de fragmentos. Natalia Álvarez (ed.). Alicante: Biblioteca Virtual Miguel de Cervantes: 3-8. Disponible en: <http://www.cervantesvirtual.com/nd/ark:/59851/bmc3b7v6>. Fecha de acceso: 26 feb. 2018.

Nerín, Gustau. 1998. Guinea Ecuatorial. Historia en blanco y negro. Barcelona: Península.

Ortiz, Fernando. 1981. Los bailes y el teatro de los negros en el folklore de Cuba. La Habana: Letras Cubanas.

Ortiz, Fernando. 1986. Los negros curros. La Habana: Editorial de Ciencias Sociales.

Overmyer-Velázquez, Rebecca. 2005. "Christian Morality in New Spain: The Nahua woman in the Franciscan Imaginary", en Tony Ballantyne y Antoinette Burton (eds.), Bodies in Contact. Rethinking Colonial Encounters in World History: 67-83. Durham/London: Duke University Press.

Periáñez Gómez, Rocío. 2008a. La esclavitud en Extremadura (siglos XVI-XVIII). Tesis doctoral. Cáceres: Universidad de Extremadura.

Periáñez Gómez, Rocío. 2008b. "La investigación sobre la esclavitud en España en la Edad Modernaw. Norba. Revista de Historia 21: 275-282.

Piqueras, José Antonio. 2011. La esclavitud en las Españas. Un lazo transatlántico, Madrid: Catarata.

Quijano, Aníbal. 2000. "Colonialidad del poder y clasificación social”. Journal of Wold-System Research $\mathrm{VI}(2): 342-386$.

Quintero, Pablo. 2010. "Notas sobre la teoría de la colonialidad del poder y la estructuración de la sociedad en América Latina". Papeles de Trabajo 19: 1-15.

Restall, Mathew. 2000. "Black Conquistadors: Armed Africans in Early Spanish America". The Americas 57(2): 171-205.

Rosales, Miguel Ángel. 2016. Gurumbé. Canciones de tu memoria negra. Documental. [S. 1.]: Intermedia Producciones.

Ruiz Collantes, Xavier, Joan Ferrés, Matilde Obradors, Eva Pujadas y Oliver Pérez. 2006. "La imagen pública de la inmigración en las series de televisión". Quaderns del Consell de l'Audiovisual de Catalunya 23-24: 107-132.

Santana, Lázaro. 1975. "Judíos, moros, guanches". Aguayro 63: 21. Disponible en: <http://mdc.ulpgc.es/ cdm/ref/collection/aguayro/id/790>. Fecha de acceso: 26 feb. 2018

Spivak, Gayatri Chakravorty. 1993. "Can the Subaltern Speak?", en Patrick Williams y Laura Chrisman, Colonial Discourse and Post-Colonial Theory: a Reader: 66-111. Hemel Hempstead: Harvester Wheatsheaf.

Stallaert, Christiane. 1998. Etnogénesis y etnicidad en España: Una aproximación histórico-antropológica al casticismo. Barcelona: Proyecto A.

Stolcke, Verena. 1995. "Talking Culture. New Boundaries, New Rhetorics of Exclusion in Europe", Current Anthropology, 36 (I): 1-24.

Stolcke, Verena. 2009. "Los mestizos no nacen sino que se hacen". Avá. Revista de Antropología 14. Disponible en: <http://www.scielo.org.ar/scielo.php?script=sci_arttext\&pid=\$1851-16942009000100002\& lng=es\&nrm=iso>. Fecha de acceso: 26 feb. 2018

Suárez Navaz, Liliana. 2011. "Políticas de representación: construcción y marketing de nuevas identidades en el espacio político-mediáticon. Revista de Antropología Social 20: 229-261.

Suárez Navaz, Liliana y Alicia Ferrández Ferrer. 2012. "Migrant Minority Media: Towards a Democratization of the Western Mediascape?", en Isabelle Rigoni y Eugénie Saitta, Mediating cultural diversity in a globalised public space: 76-95. Londres/Nueva York: Palgrave Macmillan.

Taylor, Diana. 1998. "A Savage Performance: Guillermo Gómez-Peña and Coco Fusco's "Couple in the Cage"”. MIT Press Journals 42(2): 160-175.

Fecha de recepción: 1 de mayo de 2017

Fecha de aceptación: 13 de diciembre de 2017

Revista de Dialectología y Tradiciones Populares, vol. LXXIII, n. ${ }^{\circ}$ 1, pp. 153-175, enero-junio 2018, ISSN: 0034-7981, eISSN: 1988-8457, https://doi.org/10.3989/rdtp.2018.01.006 